\title{
Religión, cultura y sociedad en Cuba
}

\author{
Jorge Ramírez Calzadilla \\ Centro de Investigaciones Psicológicas y Sociológicas (CIPS). \\ D epartamento de Estudios Sociorreligiosos (DESR). \\ Calle B \#352, esquina 15. Vedado. 10400 La H abana. Cuba
}

Fecha de recepción: noviembre de 1995

\section{Resumen}

El cuadro religioso cubano presenta una peculiar complejidad por la diversidad de formas y organizaciones religiosas que lo componen y en especial por las notables diferencias entre ellas. Esto responde a que históricamente se han establecido distintos modelos socioculturales que han aportado modos distintos de expresar la religiosidad.

De la cultura aborigen, quedan algunas huellas poco perceptibles. Los modelos más importantes, el español y el africano, establecieron respectivamente el catolicismo con carácter hegemónico y expresiones cubanizadas conformadas en un proceso de transculturación. El modelo norteamericano importó el espiritismo y más de 50 denominaciones protestantes. Por otras influencias se han incorporado el vodú haitiano, formas religiosas de chinos, el judaísmo, etc.

Si bien en la mayoría de la población existen elementos religiosos, el pueblo cubano sin embargo no es eminentemente católico, protestante, santero o espiritista. Prevalece una religiosidad espontánea, asistemática, referida principalmente a la cotidianeidad que se expresa en variadas devociones, creencias y prácticas de contenido más bien mágico y supersticioso.

Se destaca que en conjunto la religión no ha alcanzado en Cuba un nivel alto de significación sociopolítica en su intervención en la reproducción de la sociedad concreta. Ha tenido sucesivos momentos de incremento y de recesión. Se han verificado momentos de reactivamiento religioso en las etapas colonial, republicana neocolonial y revolucionaria. Actualmente, coincidiendo con una crisis socioeconómica se constata un reactivamiento religioso, debido a múltiples factores, desde 1989 y más aún en los años noventa.

Palabras clave: religiosidad, expresión religiosa, religiosidad popular, significación social de la religión, reactivamiento religioso, modelo sociocultural, cuadro religioso cubano.

Abstract. Religion, cultureand society in Cuba

There are several religious forms and organizations in Cuba. Religiosity is shown in different sociocultural models. There are several cultural models: Spanish, African, $\mathrm{N}$ orthamerican, $\mathrm{H}$ aity vudú, Chinese religious practices, etc. which have influenced Cuban religious believes and practices.

H owever Cuba is a Catholic country and religion has no sociopolitical signifcance, except for a slight increase of religiosity since 1989-1990.

Key words: Religiosity, popular religiosity, sociocultural model of Cuban religiosity. 


\section{Sumario}

$\begin{aligned} \text { Modelos socioculturales } & \text { El reactivamiento en condiciones } \\ \text { y conformación del cuadro religioso } & \text { de crisis social } \\ N \text { iveles de distribución de } & \text { Anexo. Clasificación de formas } \\ \text { la religiosidad en la población } & \begin{array}{l}\text { concretas y agrupaciones que } \\ \text { conforman el cuadro religioso cubano }\end{array}\end{aligned}$

Al igual que en otros muchos países modernos - en especial en los que la nacional idad se conformó con el aporte de diferentes pueblos como en los latinoamericanos y caribeños - , la sociedad cubana presenta una destacada diversidad en el campo religioso derivada en su caso específico, como característica fundamental, de un mestizaje racial, cultural, incluso religioso y hasta económico, resultante de un proceso acertadamente denominado de transculturación ${ }^{1}$, a partir de la conquista y colonización europea con la abrupta llegada de los españoles, que imprimieron nuevos cauces al curso histórico.

Reiteradamente se admite que Cuba es un crisol de culturas, una síntesis de diferentes raíces, desde las más antiguas e influyentes hasta otras posteriores o con incidencia menos destacada. Los etnólogos coinciden en estimar que más del $80 \%$ de la población cubana actual es mestiza, aunque en unos predominen rasgos típicos de negros y en otros de blancos por entrecruzamientos anteriores que se siguen produciendo. La economía, por su parte, se caracteriza por la concurrencia en una misma etapa de relaciones propias de diferentes sistemas socioeconómicos, ninguno de los cuales - esclavista, feudal, capitalista o socialista- ha alcanzado madurez de desarrollo ni coincidencia con modelos puros.

En esa interrelación y fusiones la religión fue adquiriendo una cierta complejidad con la que se manifiesta en una multiplicidad de formas concretas. En su conjunto, el fenómeno religioso cubano es heterogéneo y contradictorio, con destacada presencia de sincretizaciones, inserta en un sistema de relaciones sociales que han determinado una cambiante pero establemente relativa significación social y singulares vínculos entre religión, etnia y raza, en una inicial asociación con lo aborigen, lo hispano y lo africano - los dos últimos con reales posibilidades de concretarse como identidad sólo en América- y una posterior cubanía que terminó por borrar distinciones de este tipo al conformarse como pueblo monoétnico.

Con autonomía de ortodoxias, pero derivada de ellas, y del imaginario popular, existe una religiosidad que es propósito de este trabajo demostrar es típica y prevaleciente en la mayor parte de la población, como lo comprueban

1. El término lo propuso y acuñó el sabio cubano Fernando O rtiz, inicialmente en su trabajo Contrapunteo del tabaco y el azúcar, en el cual la interacción cultural verificada es mejor designada que con aculturación o inculturación.

2. Se trata del conjunto de investigaciones del D epartamento de Estudios Sociorreligiosos (D ESR ), colectivo multidisciplinario que estudia la religión en Cuba, y en menor medida en América Latina, cuyos resultados, algunos de los cuales serán referidos, respaldan los datos y las reflexiones aquí sostenidos. 
investigaciones realizadas², descalificando así criterios acerca de un supuesto indiferentismo característico de la sociedad cubana en diferentes momentos. Las peculiaridades religiosas presentan semejanzas con el campo religioso latinoamericano y caribeño, con cuyos pueblos el cubano participa de una identidad cultural, aunque a la vez hay notables diferencias, en especial por una menor intervención de la religión en la vida social, si bien se han verificado momentos de incremento como un actual reavivamiento religioso que acompaña a condiciones de crisis.

\section{M odelos socioculturales y conformación del cuadro religioso}

La complejidad del cuadro religioso conformado en la sociedad cubana responde a la variedad de formas religiosas distinguibles entre sí por su origen, el contenido de sus ideas y representaciones, los modos de organizarse y de expresar el ritual, el enfoque de la sociedad, su inserción y el nivel de influencia en ella. En esto ha incidido básicamente la referida multiplicidad cultural. Varios modelos socioculturales han concurrido simultáneamente y en sucesivas etapas acompañados de formas religiosas concretas.

El primero y más antiguo de esos modelosesel aborigen. Los pueblos autóctonos no alcanzaron los niveles de desarrollo de las culturas mesoamericana e incaica. Su religión no intervenía tan significativamente en la reproducción de la sociedad como en aquéla donde el poder y los elementos fundamentales para la vida (la tierra, la cosecha, etc.) estaban sacralizados. Tampoco la dominación española tuvo iguales repercusiones. M ientras el sistema de vasallaje permitió la conservación de rasgos cultural es aborígenes en regiones de Latinoamérica, perdurando originales ritos, símbolos y concepciones ${ }^{3}$, las encomiendas en Cuba, derivadas en forma de esclavitud, daban poco espacio a una influencia cultural en condiciones que por demás determinaron la desaparición de aque Ilas comunidades étnicas. N o obstante, al gunos rasgos no podían ser borrados y de algún modo hubo aportes aborígenes a la religiosidad cubana, como lo proponen recientes estudios 4 .

La vertiente española del modelo occidental, establecida largamente como cultura dominante por más tiempo en Cuba que en la mayoría de las restantes colonias del continente y prolongada en otras circunstancias, rotos los vínculos con la M etrópoli, por la permanencia en el país de españoles incorporados sobre todo a sectores comerciales y agrícolas y por posteriores inmigraciones, implantó el catolicismo en calidad de religión oficial y hasta exclusiva. Sobre este catolicismo es necesario tener en cuenta tres factores que lo condicionaron:

3. La literatura al respecto de arqueólogos, antropólogos y folcloristas que describen la influencia aborigen es muy rica y extensa. En torno a la religiosidad popular los textos son también abundantes. Las fuentes y las características que se apuntan los hemos examinado anteriormente, por ejemplo en: M ONTAGn E, F.; RAm íREZ, J. (1994). Formas religiosas populares en América L atina. La H abana: Editora Política, Colección Voces, La H abana.

4. Ver FARIÑ AS, M.D. (1995). La religión en las Antillas. Paralelismo y transculturación. La $\mathrm{H}$ abana: Editorial Academia. 
por una parte, la dependencia de la I glesia católica a la C orona de España, y una subordinación de las estructuras eclesiales locales a las españolas con un estilo de actuación y unas concepciones propias de ese país, por otra parte, el clero que acompañó a la empresa colonial y por mucho tiempo no fue un modelo ético ni de dedicación, sobre lo que hay hechos que lo confirman; por último, el tipo de catolicismo importado cerrado a las tendencias renovadoras de la Reforma, con fuertes influencias moriscas, judaizantes y de supersticiones medievales, no era realmente el catolicismo de los grandes místicos, sino más próximo al Ilamado catolicismo popular español. Por razones políticas y de actuación pastoral, en resumen, el catolicismo en su forma ortodoxa no alcanzó niveles altos de arraigo en la sociedad cubana y en su contra incidió un anticlericalismo que permeó el pensamiento más avanzado e influyente 5 .

El modelo sociocultural africano, constituido, al igual que el español, por un conjunto de culturas de diferentes pueblos, aportó distintas formas religiosas que en las condiciones cubanas fueron modificándose hasta conformar las actuales expresiones cubanizadas, entre ellas la R egla 0 cha o santería, de origen yoruba, la Regla Conga o palo monte, de ascendencia bantú, las sociedades secretas masculinas Abakuá, similares a nigerianas, y otras menos exten-

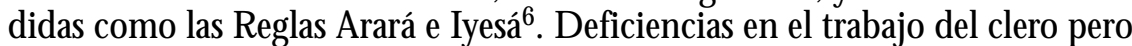
más aún el hecho de que cristianizar al negro le ofrecía al esclavo un rango de igualdad que no quería el esclavista, al que además no convenía reducir las jornadas de trabajo para la instrucción religiosa ni el cumplimiento de días de precepto, unido a que en el conservar diferencias étnicas, lingüísticas y religiosas evitaban la unión en dotaciones y posibles sublevaciones, decidieron que la evangelización del africano y sus descendencias no fuese efectiva, primase una cierta tolerancia práctica por encima de disposiciones formales y se verificase una sincretización entre elementos del santoral católico y de las mitologías africanas.

Aunque difundidas en la población, las expresiones de origen africano no podían constituirse en la religión característica del cubano por la ausencia de estructuras organizativas idóneas, al ser parte de la cultura dominada, y las subestimaciones y discriminaciones sobre ellas sostenidas por largo tiempo. No tener en cuenta las profundas diferencias del modelo africano y valorarlo aplicándole criterios occidentales, contribuyeron a prejuicios e incluso a la consideración de religiones amorales. Las recientes investigaciones demuestran un sistema de valores aun cuando sean bien diferentes los códigos cristianos ${ }^{7}$.

5. Sobre las características del catolicismo en Cuba y un análisis de su evolución, recomendamos consultar: COLECTIVO DE AUTORES (1990): La religión en la cultura, D ESR, Editorial Academia, La H abana.

6. Sobre estas expresiones hay una literatura en especial descriptiva y desde ángulos folclóricos y culturológicos. Fernando O rtiz es consulta obligatoria. Para un análisis desde una perspectiva sociológica ver: ARGÜ ELLES, A.; H O D GE, I. (1991). L osllamados cultos sincréticos y el espiritismo. La H abana: Editorial Academia.

7. Argüelles, A.; Perera, A.C . (1995). El sistema de valores en la Regla O cha. La H abana: DESR (inédito). 
La vertiente norteamericana del modelo occidental arribó a Cuba en la segunda mitad del pasado siglo y con más influencia en el $x x$ al aplicarse el proyecto neocolonial con que se construyó la república desde la intervención estadounidense en 1898. Con él llegó el espiritismo, aunque teorizado desde Francia y más extendido en la población cubana en variantes alejadas de la teoría, de carácter básicamente utilitario y sincretizado con el catolicismo y expresiones de origen african $0^{8}$. Introdujo también el protestantismo reproduciendo modalidades con que se fraccionó en los Estados U nidos, alcanzando la cifra de 54 denominaciones evangélicas en el país. Primeramente se instaló por cubanos que compartían actividades independentistas a finales del siglo xIX, por lo que han sido llamados misioneros patriotas los que poco después fueron desplazados por norteamericanos con apoyo de las Juntas $M$ isioneras que le imprimieron una orientación norteamericanizante al protestantismo en su acción

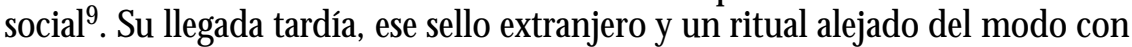
que la mayoría de los creyentes expresan sus creencias y vínculos con lo sobre natural, han incidido en que tampoco el protestantismo capitalizase la religiosidad cubana, para lo cual realmente ha dispuesto de menos posibilidades que otras expresiones instaladas con anterioridad.

La cultura cubana ha recibido otras influencias con derivaciones religiosas que aunque menos extendidas hacen aún más complejo el cuadro religioso. Braceros haitianos inmigrados para satisfacer demandas de la cosecha azucarera en la etapa republicana neocolonial eran portadores del Ilamado vodú, que refleja los sincretismos de religiones africanas y el catolicismo. Entonces y desde antes fueron contratados campesinos chinos bajo condiciones de semiesclavitud, los cuales tenían sus propias creencias y prácticas religiosas muy poco estudiadas en Cuba. Inmigrantes de nacionalidad hebrea instituyeron en el país el judaísmo con varias organizaciones y sinagogas. Formas filosófico-religiosas orientales, como el bahaísmo, el teosofismo y otras son también estudiadas y practicadas (ver en el anexo del final del artículo una clasificación de expresiones y organizaciones religiosas existentes en Cuba).

Un primer hecho, en conclusión, se constata en el cuadro religioso cubano, y es que ninguna expresión religiosa organizada ha logrado prevalecer de modo que llegue a caracterizar la religiosidad en la sociedad, aun cuando unas - en específico: catolicismo, espiritismo y santería - han al canzado mayor capacidad de influencia que otras. Puede afirmarse que el pueblo cubano no es eminentemente católico, si bien muchos sin una práctica consecuente e ideas religiosas difusas declaran ser católicos; ni protestante, cuya membresía en conjunto nunca ha sido notoriamente alta; ni santero; palero o ñañigo; ni espiritista; a pesar de la difusión que estas expresiones han alcanzado incluso frecuentemente entremezcladas.

8. HOdGE, I.; Rodríguez, M . (1995). M odos de manifestarse el espiritismo en Cuba. La H abana: DESR (inédito).

9. CePEDA, R. (1985). «Las iglesias protestantes norteamericanas en la política expansionista de 1898, su reflejo en Cuba», en Cristianismo y Sociedad, núm. 86, M éxico, p. 35-61. 
Un problema entonces se plantea en el examen del fenómeno: ¿acaso el pueblo cubano es no creyente o indiferente?, si no es así, ¿qué tipo de religiosidad es predominante a nivel social? H asta aquí se han aportado al gunos elementos que adelantan una respuesta, pero no cabe duda que es necesario un análisis más profundo y detallado.

\section{N iveles de distribución de la religiosidad en la población}

D istintos observadores y analistas de la sociedad cubana en épocas distantes entre sí, coinciden en apuntar lo que consideran una relativa débil religiosidad. Fernando 0 rtiz llegó a afirmar que lo que la caracteriza en materia religiosa es el indiferentismo ${ }^{10}$. Con ello coincidió posteriormente el historiador y pastor presbiteriano Rafael C epeda ${ }^{11}$. Antes, a mediados del siglo XIX, N icolás Tarrea consideró que «los habaneros debieran ser católicos pero muchos son indiferentes ${ }^{12}$. Por esa época la prestigiosa novelista sueca Fredrika Bremer apuntó: «Entre los extranjeros de diferentes nacionalidades establecidos en Cuba, hay una sola y misma opinión sobre la ausencia de vida religiosa en la is $a^{13}{ }^{13}$, Un estudio reciente de The American U niversity sobre la religión en la etapa prerrevolucionaria concluía que «C uba era predominantemente un país no religioso» y cita a M argaret $\mathrm{E}$. Crahan del $\mathrm{O}$ ccidental College, quien calificó la práctica religiosa de «relativamente significativa ${ }^{14}{ }^{4}$.

Realmente este indiferentismo está referido a formas ortodoxas cristianas, en especial del catolicismo que debió ser, por su ubicación en las estructuras del poder, el sistema religioso más significativo. Esta debilidad fue en cierto modo admitida por el arzobispo de la $\mathrm{H}$ abana en 1982 al decir que siempre las comunidades de practicantes han sido poco numerosas ${ }^{15}$, y por un análisis realizado por cristianos que reconocían la existencia de una masa de creyentes que no participan en las organizaciones eclesiales ${ }^{16}$. La Agrupación Católica Universitaria (ACU) en 1953 recogía en las conclusiones de una encuesta nacional que las membresías parroquiales sólo representaban entre un 2 y un $8 \%$ de la población en sus respectivas zonas ${ }^{17}$.

10. O RTIZ, F. (1917). Los negros brujos. M adrid: Ed. América, p. 252.

11. CepedA, R. (1985). O p. cit.

12. Tarrea, N . (1981). «La isla de Cuba», en Juan Pérez de la Peña: La isla de Cuba en el siglo xIX vista por un extranjero. La H abana: Ed. Ciencias Sociales.

13. BRem ER, F. (1981). Cartas desde Cuba. La H abana: Ed. Letras Cubanas, p. 148.

14. Rudo LPH, J.D. (editor) (1987). Cuba, a country study, Foreign Area Studies, The American University, 3a. edición, U SA, p. 85-86.

15. Encuentro Diocesano de Pastoral (1982), folleto publicado por la arquidiócesis de La H abana, La H abana. En él aparecen una intervención del arzobispo, M ons. Jaime 0 rtega, actualmente y desde noviembre de 1994, cardenal, en la que hace referencia a la religiosidad en el pueblo, que en su opinión tiene un fundamento católico, aunque admite contradictoriamente con una ausencia de práctica ortodoxa que es lo que en verdad se constata.

16. Primer Encuentro Latinoamericano de Cristianos por el Socialismo. La H abana: Ed. Camilo Torres, 1979, p. 66-67.

17. Encuesta nacional sobre sentimientos religiosos en el pueblo de Cuba, Buró de Información de la Agrupación C atólica Universitaria, La H abana, 1954. 
Cálculos del D ESR basados en observaciones, datos censales católicos y cifras de miembros reconocidos por iglesias protestantes permiten estimar que por los años ochenta la feligresía activamente cristiana no llegaba a representar un $2 \%$ de la población cuban $a^{18}$ (el total poblacional entonces era algo más de 10 millones); sin embargo esto ha variado posteriormente con un crecimiento que anal izaremos más adelante. Los miembros de grupos de expresiones de origen africano y espiritistas se consideraban en conjunto en cantidades algo más altas, aunque su débil institucionalización organizativa impide precisiones.

Paralelamente, los principales acontecimientos nacionales han tenido una connotación ante todo laica, aunque lo religioso ha intervenido pero en un grado mucho menos sensible que en otros países latinoamericanos. Es decir, la religión en Cuba ha alcanzado obviamente una significación social, entendiendo por tal la influencia y capacidad de intervenir en los procesos sociales, pero el nivel de su significación ha sido regularmente bajo.

La razón de tal comportamiento, a partir de las propuestas de François $\mathrm{H}$ outart ${ }^{19}$, se encuentra en la interrelación entre las condiciones sociales de vida y las representaciones religiosas. En Cuba los sistemas socioeconómicos establecidos en diferentes etapas, colonial, republicana neocolonial y revolucionaria, han encontrado en sus propias relaciones sociales los mecanismos suficientes para la reproducción de cada sociedad concreta y la ideología ha tenido en ellos los elementos para construir su justificación, sin necesidad de recurrir como elemento básico a lo metasocial, para lo cual lo sobrenatural, y por tanto la religión, se presentaría con la fuerza que se le concede por encima de las variaciones sociales. $\mathrm{Ni}$ el esclavista con la coerción sobre los esclavos, ni el capitalista con las leyes de la ganancia, el salario, la movilidad social y la violencia en caso necesario, requerían, mientras esos recursos conservaron la excelencia, de la religión como imprescindible, aun cuando la manipulasen en su apoyo. El socialismo por definición tiene en las conquistas sociales los medios idóneos para la concertación de las mayorías en función de la conservación y reproducción del sistema. C ada sistema construyó su lógica de reproducción sobre la base de elementos de la propia sociedad y no fuera de ella 20 .

Las investigaciones en zonas rurales cubanas han constatado que los creyentes en esa población, en su mayoría no están vinculados a una expresión religiosa determinada ni son miembros de algún grupo religioso, lo que reporta una escasa actividad de las organizaciones religiosas con una mayor influencia del espiritismo, si bien en minoría. Las creencias y las prácticas predominantes

18. Colectivo de Autores (1989). La conciencia religiosa. Característicasy formas de manifestarse en la sociedad cubana contemporánea. Informe de investigación. La H abana: DESR (inédito). Una versión más actualizada (1993) con igual título está en edición.

19. Entre otros trabajos de este destacado sociólogo de la religión, puede revisarse: H OUTART, F. (1989). Religión y modos de producción precapitalistas, Editions de l'Université de Bruxelles. M adrid: Editorial IEPALA.

20. Una argumentación más completa se puede encontrar en RAm íREZ, J. (1994): Religión y relaciones sociales. La H abana: DESR (en edición). 
tienen un contenido más bien mágico y supersticioso referido principalmente a curaciones, espíritus, luces, aparecidos, el mal de ojo y otras similares ${ }^{21}$.

El anterior es un estudio antropológico con técnicas sociológicas que se realizó en la década de los ochenta y abarca 121 zonas rurales de siete de las 14 provincias del país. No es representativo estadísticamente de la población rural, aunque ofrece una visión aproximada de la realidad. Según las variables entonces definidas se encontró que las creencias y las prácticas se daban en mayor medida en las personas que no se definían en una expresión religiosa organizada, en un primer nivel que se caracteriza por considerar reales nexos ine xistentes o meramente casuales entre objetos y fenómenos, por encima de los también no definidos que llegaban a personificar lo sobrenatural (lo que puede estar indicando cierta diferencia en la religiosidad rural respecto a la urbana según los datos que más adelante se recogen en una muestra nacional); ambos presentan proporciones más altas que la de los que se definían dentro de un sistema religioso determinado y los no creyentes, como se constató en la sociedad en general. Esto se advierte en la tabla 1.

Estudios sistemáticos desde 1983 sobre las festividades religiosas más concurridas en las que se veneran figuras preferenciadas popularmente (san Lázaro, la $C$ aridad, la Virgen de Regla, la M erced y santa Bárbara, sobre las cuales confluyen versiones, leyendas, mitos católicos y yorubas con la imaginación del pueblo $)^{22}$ en determinados templos y fechas y en celebraciones domésticas, arrojan una asistencia que supera la membresía de cualquier iglesia y las de varias juntas. Cálculos sobre la devoción a san Lázaro, la de mayor concurrencia, permiten estimar que en ella participa más del 1,5\% de la población, según datos que posteriormente se ejemplifican, es decir, por encima de 150.000 asistentes a los distintos locales de culto. Estos creyentes, procedentes de diferentes zonas del país y de diversas ocupaciones (ver tabla 2), mayoritariamente no son asiduos a templos católicos ni a ceremonias de otras expresiones, sus creencias no se inscriben en sistemas religiosos organizados y sus motivacio-

21. Ver: Creencias y prácticas religi osas en zonas rurales (1989). La H abana: DESR (impresión ligera) y La religión en la cultura, op. cit.

22. En esta sincretización han intervenido leyendas, atributos, colores. Por ejemplo, la C aridad del Cobre, símbolo del amor cristiano, se asoció con la deidad yoruba $O$ chún, que en Cuba representa las aguas dulces y la miel; la V irgen de Regla, cuya imagen es morena y su templo se ubica a la entrada del puerto de La H abana, fue sincretizada con la también yoruba Yamayá, deidad de las aguas profundas, cuyo color es azul como la túnica de la figura católica; la M erced, de vestimenta blanca, se identificó con 0 batalá, deidad yoruba principal de la pureza; la imagen católica de santa Bárbara se acompaña con una espada y una torre recordando su encierro y decapitación, de ahí su afinidad con C hangó, yoruba, dios de la guerra cuyo color es el rojo igual que el de la mártir cristiana; san Lázaro tiene una versión oficial en Lázaro de Betania, resucitado y luego martirizado, pero también en el viejo de la parábola evangélica del leproso y el rico Epulón, lo que facilitó la simbiosis con Babalú Ayé, dahomeyano, en cuya mitología se cuenta sufrió la mendicidad y la lepra hasta que por último se le restituyeron sus poderes en tanto deidad. Ver COLECTIVO DEL DESR (1989). Lasfestividades religi osas más concurridas como fenómeno quetipifica la religiosidad cubana. La H abana: DESR (mimeógrafo). 
Tabla 1. Categorías de creencias y prácticas religiosas en zonas rurales (1988).

\begin{tabular}{lc} 
Categorías & $\%$ \\
\hline No creyentes & 13,8 \\
Vacilantes & 10,4 \\
Creyentes no definidos del nivel I & 55,9 \\
Creyentes no definidos del nivel II & 13,6 \\
Creyentes definidos & 6,3 \\
& $(\mathrm{~N}=1135)$
\end{tabular}

Fuente: Estudio realizado en la década de los ochenta, en 121 zonas rurales de 7 provincias.

Tabla 2. Asistentes a templos los días de San Lázaro y la C aridad, por ocupaciones, según entrevistas (1983-1988)*.

\begin{tabular}{lc}
\hline O cupación & \% promedio en ambas festividades \\
\hline O brero & 19,9 \\
Ama de casa & 23,0 \\
Estudiante & 10,6 \\
Técnico & 6,3 \\
Trabajador de servicios y administrativo & 18,2 \\
Jubilado & 9,9 \\
Profesional & 4,5 \\
Trabajador por cuenta propia & 1,9 \\
Campesino & 3,6 \\
$\quad$ (cooperativista y pequeño agricultor) & 10,6 \\
O tros & 1,0 \\
N o dijo & $(\mathrm{N}=1135)$ \\
\end{tabular}

Fuente: Las festividades religiosas más concurridas como fenómeno que ti pifica la religi osidad cubana, D epartamento de Estudios Sociorreligiosos, La H abana, 1989 (mimeógrafo).

* Asistentes al Santuario de El Rincón (Ciudad de La H abana) el día de San Lázaro y a los Santuarios de El Cobre (Santiago de Cuba), Centro H abana y Regla (Ciudad de La H abana) e iglesia de C amagüey, el día de la C aridad.

nes se asocian a problemas terrenales en la vida cotidiana (salud, protección, solución de los más variados problemas familiares y personales).

Por el conjunto de éstas y otras actividades investigativas se ha precisado que la religiosidad cubana se expresa en tres niveles principales de organización de la ídea de lo sobrenatural. El más bajo, de ideas poco estructuradas y contenido mágico supersticioso. 0 tro intermedio en el que lo sobrenatural aparece personificado generalmente en figuras consideradas en sí mismas milagrosas sin que ocupen un lugar en un sistema religioso. El nivel de más alta elaboración incluye los sistemas de las expresiones religiosas y supone la posibilidad de pertenencia a una agrupación religiosa. 
Tabla 3. Distribución porcentual de los grupos por presencia o no en la conciencia de elementos religiosos en la población (1989)

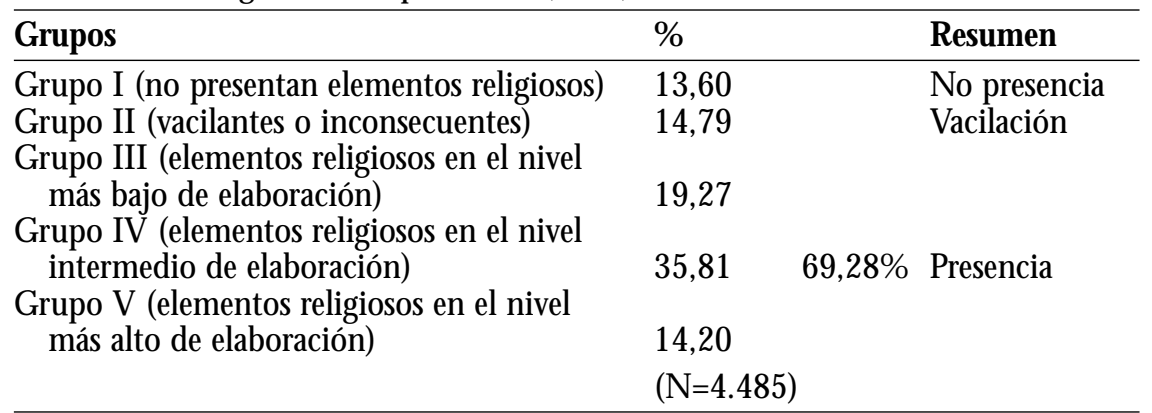

Fuente: La conciencia religiosa. Características y formas de manifestarse en la sociedad cubana actual, D epartamento de Estudios Sociorreligiosos, CIPS (inédito).

Con esta estructura se constató en la conciencia de las personas la presencia de elementos religiosos en cualquiera de los niveles descritos, la no presencia o la vacilación, con lo que se conformaron cinco grupos. D e acuerdo con ello, al concluir la década de los ochenta, en más de un $65 \%$ de la población, amplia ble a cerca del $85 \%$ si se incluye la presencia en forma de vacilación o duda (grupo II), existían de un modo u otro creencias en lo sobrenatural. Los no creyentes (grupo I), por tanto, constituían una proporción reducida. Estas creencias tenían un carácter ante todo espontáneo, asistemático, organizadas a un nivel bajo (grupo III) y mayoritariamente intermedio (grupo IV), advirtiéndose en conjunto en más del $50 \%$ de la población. Las creencias que comportan mayor estructuración y sistematización (grupo V) se encontraban en una parte minoritaria ${ }^{23}$ (ver tabla 3 ).

El comportamiento de los indicadores de religiosidad demuestran por qué los grupos IV y III determinan el tipo de religiosidad prevaleciente en el cubano, al ser sus indicadores específicos los más apuntados y estar distribuidos en los tres grupos que comportan creencias. Los porcentajes más altos corresponden a creencias asociadas a la práctica, reflejan ideas imprecisas sobre la muerte, curaciones mágicas, la suerte, el contacto con espíritus, los rezos y ceremonias como vía para solucionar problemas. En la medida que se acercan a ortodoxias las cifras decrecen, siendo menos señalada la pertenencia a una agrupación religiosa (ver tabla 4).

23. La muestra estudiada estaba conformada por diferentes sectores. Los resultados arrojaron que la presencia de elementos religiosos a un nivel u otro de elaboración en la conciencia era estadísticamente significativa en amas de casa, obreros, campesinos y desvinculados del trabajo y el estudio; en intelectuales era significativa la no presencia y en los estudiantes la relación entre ambas variables no alcanzó diferencias significativas (ver: La conciencia religiosa. Características... , op. cit.). 
Tabla 4. Comportamiento de indicadores de religiosidad en los sujetos creyentes.

Indicadores o grupos de indicadores $\%$ de sujetos que los señalaron

- Considerar que el momento de la muerte está predeterminado o es posible que lo esté.

- Indicadores de contenido práctico-mágicos referidos a curaciones, acciones para tranquilidad de los muertos, figuras milagrosas.

- Indicadores sobre existencia de espíritus, aparecidos y la comunicación con los muertos.

74,36

entre 65,26 y 40,35

entre 40,06 y 20,22

- Considerar que es bueno y deben celebrarse bautizos, fiestas de santos y la semana santa.

entre 17,55 y 15,36

- Admitir la asistencia a actividades religiosas, acudir a dirigentes de culto y visitar hermanos de grupo religioso. entre 6,70 y 3,19

- Admitir la pertenencia a una agrupación religiosa

Fuente: La conciencia religiosa...

La religiosidad más extendida en la sociedad cubana, en resumen, se caracteriza por ser espontánea, con relativa autonomía de formas organizadas (aunque ha incorporado elementos del catolicismo, de las expresiones de origen africano y del espiritismo), asociada a la vida cotidiana en términos más bien utilitarios.

\section{El reactivamiento en condiciones de crisis social}

Es opinión generalizada que el mundo contemporáneo asiste a una crisis tanto en lo económico, con una creciente pobreza, desigualdades entre naciones, estancamientos del desarrollo, como en el campo social y de la vida espiritual por injusticias, discriminaciones, conflictos étnicos, consumismo desbordado, un materialismo vulgar y la ilógica destrucción del medio ambiente. Se afirma repetidas veces que se produce una crisis de racionalidad, de paradigmas y de valores. Es en realidad un cuestionamiento de la racionalidad, de los mode los y de los valores con que se ha construido la modernidad que han conducido a la humanidad a una tal situación. Por ello hay quienes reiteradamente aseguran que el hombre de hoy día está necesitado de utopías y que se accede a una vuelta a la religión ${ }^{24}$. Lo cierto es que, como en otras ocasiones, la religión incrementa su importancia y su papel en momentos de crisis.

Cuba no escapa a esta coyuntura de alcance universal, y en su caso particular ello se agrava con una situación crítica en la economía, de serias pro-

24. Ver, por ejemplo, Betтo, F. (1991). «M ística y socialismo», en revista Casa, C asa de las Américas, núm. 185, octubre diciembre, La H abana, y Bo FF, L. (1993). «Religión, justicia societaria y renacimiento», en revista Pasos, núm. 45, enero-febrero, San José de Costa Rica, p. 1-10. 
Tabla 5. C antidad de bautizados y de bautizos por años (frecuencia bianual) en Cuba.

\begin{tabular}{llll}
\hline Año & $\begin{array}{l}\text { Total de } \\
\text { bautizados }\end{array}$ & $\begin{array}{l}\text { C antidad } \\
\text { de bautizos }\end{array}$ & $\begin{array}{l}\text { Bautizos en la arquidiócesis } \\
\text { de La H abana }\end{array}$ \\
\hline 1986 & 4.141 .600 & 26.534 & 15.664 \\
1988 & 4.002 .000 & 34.440 & 20.157 \\
1990 & 4.110 .000 & 58.130 & - \\
1992 & 4.857 .000 & 68.948 & - \\
1994 & - & 70.081 & 32.375 \\
\hline
\end{tabular}

Fuente: Anuario Pontificio del Vaticano de cada uno de los años correspondientes.

porciones, que ha afectado a otros campos y con riesgos en la vida social en general. A condiciones de esta naturaleza se le ha dado en llamar período espe cial, el cual se comenzó a prever y a sentir desde el inicio de la desintegración del campo socialista - con quien sostenía el mayor volumen de su comercio exterior - al terminar la década de los ochenta, y en especial durante los primeros años de los noventa, presentando en 1995 algunos signos de recuperación.

Una derivación de las consecuencias del período especial es un notable reactivamiento religioso constatable en un conjunto de indicadores cuantitativos y, más aún, cualitativos. Este fenómeno se advierte en un aumento de la asistencia a ceremonias religiosas según reportan iglesias y dirigentes de culto (sacerdotes, pastores, babalaw0s, etc.); crece el número de bautizos con un salto en los noventa, en relación a 198825. En 1988 en Cuba se celebraron 14.440 bautizos, en 1990 fueron 58.130 y 70.081 en 1994, que se concentraron en la arquidiócesis de La H abana, que incluye la capital del país (ver tabla 5).

0 tras ceremonias (iniciaciones de santería, responsos y otros ritos mortuorios) son muy solicitadas; se producen las cifras más altas de participantes en las festividades más concurridas (el salto se produce en la devoción a san Lázaro, también en 1989, con un incremento en las 36 horas en que habitualmente se da la asistencia más alta de 11.100 personas más que en 1988, alcanzando en 1995 la cantidad superior, ver tabla 6); se observa una mayor utilización de signos religiosos visibles (crucifijos, collares, pulsos, vestimentas); son más numerosos los vendedores de artículos religiosos y de usos rituales en los alrededores de templos y en el comercio cuentapropista; es más notable la presencia de lo religioso en la música popular, la literatura y la plástica; hay una demanda creciente de textos religiosos (especial mente relacionados con expresiones de origen africano), y otros muchos indicadores más.

25. Según datos del ejemplar correspondiente del Anuario Pontifi cio que edita el Vaticano. El bautismo en Cuba no es un indicador de catolicidad porque generalmente se pide y se recibe sin un sentido sacramental, sino más bien de protección, aunque sí es indicador de religiosidad. 
Tabla 6. Asistencia por años al santuario de El Rincón (devoción a san Lázaro).

\begin{tabular}{ll} 
Años & Asistentes \\
\hline 1988 & 68.800 \\
1989 & 79.900 \\
1990 & 86.700 \\
1991 & 85.600 \\
1992 & 90.300 \\
1993 & 93.000 \\
1994 & 96.000 \\
1995 & 97.000
\end{tabular}

Fuente: D epartamento de Estudios Sociorreligiosos (observaciones anuales).

A nuestro modo de ver, lo importante en este incremento no es tanto si se produce o no un aumento de los creyentes sobre los no creyentes, sino que la religión ha alcanzado una mayor capacidad de intervenir en la vida social y en la de los individuos creyentes. Se trata de un hecho sociológico que no tiene necesariamente una lectura política, como se pretende presentar en cierta literatura y propaganda sobre Cuba desde el extranjero.

Las razones por las que se produce este reavivamiento son numerosas. Siendo la religión un fenómeno multideterminado, interactuante con diversos aspectos, incidente en muchos campos de la vida social e individual, sus movimientos no pueden ser explicados por un solo factor o un número re ducido de ellos, sino por un conjunto o más bien un sistema de factores que operan en una relación causal. Pero no cabe duda que insatisfacciones, desorientaciones, sentimientos de desprotección, que caracterizan las crisis sociales, potencian el recurso religioso como explicación, respaldo, esperanza y la búsqueda de protección en lo sobrenatural.

$\mathrm{N}$ o es éste el primer reactivamiento religioso en Cuba, se han verificado otros anteriores también acompañando situaciones de crisis, como durante las guerras independentistas, los conflictos sociales y políticos de los años treinta y a finales de los cincuenta. Las consecuencias a nivel social y al interior de la religión pueden ser variadas, unas transitorias y otras con más permanencia. Por lo pronto se advierte que se acentúa la tendencia al movimiento hacia las formas religiosas popularizadas asociadas a la cotidianeidad y a la solución milagrosa, menos comprometedoras en el plano ético y organizacional, a la vez que, por otra parte, hay una búsqueda en la religión de solidaridad, de ideales de vida, de valores morales, de modelos de conducta y esperanzas. El carismatismo, por su incidencia en curaciones con la sanidad divina, sus cantos movidos, el trance, que hacen que su liturgia esté próxima al modo con el que el común de los creyentes cubanos acostumbra a expresar su religiosidad, parece ser que tiene condiciones favorables para un crecimiento, como ya se advierte. 


\section{Anexo. Clasificación de formas concretas y agrupaciones que conforman el cuadro religioso cubano}

\section{Cristianismo}

1. I glesia católica: actualmente está organizada en ocho diócesis con cerca de 600 templos en total. Cuenta con un cardenal, 10 obispos, 235 sacerdotes, 23 hermanos y 465 religiosas, que totalizan 734, de los cuales el 55\% es extranjero y el $48,9 \%$ se concentra en la arquidiócesis de $\mathrm{La} \mathrm{H}$ abana. D ispone de 2 seminarios, 3 hospitales y edita varias publicaciones. Existen relaciones diplomáticas entre Cuba y el Vaticano.

2. Iglesias protestantes: en conjunto poseen cerca de 900 templos, más de un centenar de casas de culto y 5 seminarios. Editan varias revistas. La casi totalidad de sus pastores y ministros son cubanos.

2.1. Protestantismo histórico (presbiterianos, metodistas, bautistas, episcopales, cuáqueros y luteranos): surgieron en Europa en la época de la Reforma. Iniciaron la fundación de obras en el país al finalizar el pasado siglo. De ellas han surgido destacados teólogos.

2.2. Protestantismo tardío (26 iglesias pentecostales y otras como adventistas, nazarenos, salvacionistas, gedeonistas, católicos liberales, igle sias de C risto): el conjunto es muy heterogéneo, integrado por iglesias creadas principalmente en el siglo XIX. Llegaron a Cuba procedentes de los Estados Unidos a lo largo de la presente centuria. $\mathrm{H}$ ay en ellas fundaciones cubanas.

2.3. Expresiones alejadas del cristianismo tradicional (Testigos de Jehová, la de mayor extensión después de la I glesia católica, y Ciencia C ristiana, integrada por dos iglesias en un solo templo y reducida membresía).

\section{Expresiones de origen africano}

C onformadas a partir de originales religiones africanas portadas por esclavos.

Se organizan en grupos independientes sin una estructura central.

Santería (Regla 0 cha): procedencia yoruba. Su culto se centra en un extenso panteón de deidades y una rica mitología.

Palo M onte (Regla C onga): es un conjunto derivado de religiones de pueblos bantú, que consideran que la fuerza de lo sobrenatural reside en la naturaleza.

Sociedades Secretas M asculinas Abakuá (ñañiguismo): de procedencia nigeriana. A diferencia de las anteriores que realizan el culto en casas templo, ellas disponen de templos localizados en la parte occidental del país. Sus agrupaciones tienen una cierta formalidad organizativa.

0 tras agrupaciones localizadas en zonas (Arará, I yesá, Longobá): están menos extendidas y ubicadas en la zona central. 


\section{Espiritismo}

D ifundido en la población. Llegó al país el pasado siglo. Tampoco dispone de una estructura organizativa central y se manifiesta en varias vertientes.

Científico o de mesa: son grupos reducidos, seguidores de la teoría de Allan K ardec, sistematizador del espiritismo.

D e cordón: más extendido en las zonas orientales. Recibe ese nombre por la forma de su culto en fila o cordón humano. H a incorporado elementos del cristianismo y de expresiones de origen africano. No se caracteriza por el dominio de la teoría kardeciana.

C ruzado: presenta un fuerte sincretismo con las Reglas $C$ onga y 0 cha. Tiene un rasgo importante de utilitariedad.

Espiritistas no organizados: prácticas domésticas de médiums.

IV. Expresiones portadas por antiguas inmigraciones económicas y sus descendencias

Tienden a decrecer al cesar el movimiento migratorio que las introdujo en el país.

Judaísmo (de nacionalidad hebrea): fundaron varias sinagogas y asociaciones. Actualmente no cuentan con rabinos. H a influido, de modo aún no suficientemente estudiado, en la cultura cubana.

Vodú: de braceros haitianos que llegaron por la demanda de fuerza de trabajo barata para la cosecha azucarera. Se instal aron en la zona oriental. El vodú es un conjunto de formas sincretizadas entre religiones africanas y el catolicismo.

Religiones de braceros chinos: eran campesinos traídos a Cuba bajo engaño y duras condiciones de vida. Su religiosidad e influencia de la misma ha sido poco estudiada.

\section{Agrupaciones filosófico-religiosas orientales}

Asamblea Bahai: cuenta con un templo y reducida membresía en varias provincias del país.

Sociedad teosófica: dispone de un local y sus miembros tampoco son numerosos.

VI. U na religiosidad espontánea, no organizada, sin conformar agrupaciones Identificable con el concepto de religiosidad popular. Es el tipo de religiosidad más extendido. En él se advierten elementos principal mente del catolicismo, expresiones de origen africano y del espiritismo, algunos de ellos sincretizados. 